\title{
Debris flow run off simulation and verification - case study of Chen-You-Lan Watershed, Taiwan
}

\author{
M.-L. Lin, K.-L. Wang, and J.-J. Huang \\ Department of Civil Engineering, National Taiwan University, Taiwan \\ Received: 20 September 2004 - Revised: 12 February 2005 - Accepted: 19 May 2005 - Published: 2 June 2005 \\ Part of Special Issue "Landslides and debris flows: analysis, monitoring, modeling and hazard"
}

\begin{abstract}
In 1996 typhoon Herb struck the central Taiwan area, causing severe debris flow in many subwatersheds of the Chen-You-Lan river watershed. More severe cases of debris flow occurred following Chi-Chi earthquake, 1999. In order to identify the potentially affected area and its severity, the ability to simulate the flow route of debris is desirable. In this research numerical simulation of debris flow deposition process had been carried out using FLO-2D adopting ChuiSue river watershed as the study area. Sensitivity study of parameters used in the numerical model was conducted and adjustments were made empirically. The micro-geomorphic database of Chui-Sue river watershed was generated and analyzed to understand the terrain variations caused by the debris flow. Based on the micro-geomorphic analysis, the debris deposition in the Chui-Sue river watershed in the downstream area, and the position and volume of debris deposition were determined. The simulated results appeared to agree fairly well with the results of micro-geomorphic study of the area when not affected by other inflow rivers, and the trends of debris distribution in the study area appeared to be fairly consistent.
\end{abstract}

\section{Introduction}

Due to the vast development of economy, usage and development of the land in mountain terrain has grown rapidly for the available land in plane area is limited in Taiwan. However, the mountain terrain in Taiwan is usually very steep and with fragile geological conditions. Heavy rainfall accompanying typhoon often caused severe hazard by inducing slope failure and debris flow. In 1996, typhoon Herb struck Taiwan, dumping more than $2000 \mathrm{~mm}$ of rainfall. Severe debris flow occurred in several subwatersheds of the Chen-You-Lan river watershed in central Taiwan as shown in Fig. 1. In order to be able to manage and mitigate the debris flow hazard, it is de-

Correspondence to: M.-L. Lin

(mllin@ce.ntu.edu.tw) sirable to simulate the debris flow route and deposition process. The objective of this research is to construct a simulation model for evaluations of potentially affected area and the degree of severity caused by debris flow in the downstream area. Such results could provide information for further risk assessment and decision making of hazard mitigation.

Models for debris flow run-off simulation are usually based on constitutive relationships, which can be developed by different process - by experiment results or theoretical considerations of velocity distributions and continuum mechanics such as Bingham model(Bingham and Green, 1919); Herschel-Bulkley model(Herschel and Bulkley, 1926); and Coulomb-viscous model(Johnson, 1970). With the development of computing techniques, numerical methods were developed to simulate behavior and characteristics of debris flow. Chen and Lee (2002) developed a Lagrangian finite element method (LFEM) based on Bingham model to analyze slurry flows run-out. LFEM is formulated to simulate general transient slurry flows with the multidirectional sliding characteristics. Arattano and Franzi (2003) used recorded data on the North-Eastern Italian Alps in 1996 to verify their mathematical models, in which a homogeneous watersediment current over a rigid bed in unsteady conditions was assumed. Uddin et al. (2001) used debris flow velocity field method to estimate motion of debris flow; while Franzi and Bianco(2001) used empirical statistical approach to estimate debris flow deposit volume. Lin et al. (2001) used FLO-2D to study the characteristics of Chui-Sue River debris flow. In this study, the model for flow simulation was established using commercially available FLO-2D program, and the microgeomorphology analysis was performed to provide information and verification of the results of model analysis.

\section{Numerical model of debris flow}

For the numerical simulation, a commercially available flow model, FLO-2D, was used to analyze the two dimensional two-phase flow. Considering the hazard caused by debris 
flow is often due to the impact of debris in the down stream area where the debris starts to deposit. Therefore, the deposition and propagation of debris flow in the deposition area are the main interest in this research. The FLO-2D model (Hübl and Steinwendtner, 2001) can simulate the deposition giving a certain mass from the upstream, and the stopping criterion comes from the governing equations, which take yield stress and viscosity into account. The model cannot take erosion of channel bank into account, which typically occurred in the up-stream area and along flow channel. However, the model is suited for simulation of flow routing and debris deposition, thus it serves the purpose of this study.

The governing equations involved in developing the FLO2D model according to O'Brien and Julien (1985) were as presented in the follow.

1. Continuity equation

$$
\frac{\partial h}{\partial t}+\frac{\partial[u h]}{\partial x}+\frac{\partial[v h]}{\partial y}=i
$$

where $h$ is the flow depth, $u$ and $v$ are the depthaveraged velocity components along the $\mathrm{x}$ - and $\mathrm{y}$ coordinates, $i$ is the excess rainfall intensity and $t$ is the time.

\section{2-D equations of motion}

$$
\begin{aligned}
& S_{f x}=S_{o x}-\frac{\partial h}{\partial x}-\frac{u}{g} \frac{\partial u}{\partial x}-\frac{v}{g} \frac{\partial u}{\partial y}-\frac{1}{g} \frac{\partial u}{\partial t} \\
& S_{f y}=S_{o y}-\frac{\partial h}{\partial x}-\frac{v}{g} \frac{\partial v}{\partial x}-\frac{u}{g} \frac{\partial v}{\partial x}-\frac{1}{g} \frac{\partial v}{\partial t}
\end{aligned}
$$

where, $S_{o x}, S_{o y}$ are the components of bed gradient in x- and y-directions, $S_{f x}, S_{f y}$ are the components of the friction gradient in $\mathrm{x}$ - and $\mathrm{y}$-directions and $g$ is the gravity acceleration.

By neglecting the last three terms in the above equations, the approximation of diffuse wave equations could be obtained. While neglecting the pressure gradient term, a kinematic wave equation could be derived. On most steep slopes, usually the application of the kinematic wave would be sufficient to model the flood wave progression.

3. Rheological model (O’Brien and Julien, 1985)

$$
\begin{aligned}
\tau & =\tau_{y}+\tau_{v}+\tau_{t}+\tau_{d} \\
& =\tau_{y}+\eta\left(\frac{\partial u}{\partial y}\right)+C\left(\frac{\partial u}{\partial y}\right)^{2}
\end{aligned}
$$

where $\tau$ is the total shear stress, $\tau_{y}$ is the yield shear stress, $\tau_{v}$ is the viscous shear stress, $\tau_{t}$ is the turbulent shear stress, $\tau_{d}$ is the dispersive shear stress, $\eta$ is the dynamic viscosity, and with $C$ denotes the inertial shear coefficient,

$$
C=\rho_{m} l^{2}+f\left(\rho_{m}, C_{v}\right) d_{s}^{2}
$$

$\rho_{m}$ is the mass density of the mixture, $l$ is the Prandtl mixing length, $d_{s}$ is the grain size of sediment, and $C_{v}$ is the static volume concentration of the sediment.

4. Bagnold (1954) gave the definition of $f\left(\rho_{m}, C_{v}\right)$ as follows

$$
f\left(\rho_{m}, C_{v}\right)=a_{i} \rho_{m}\left(\left(\frac{C_{*}}{C_{v}}\right)^{1 / 3}-1\right)
$$

where, $a_{i}$ is the empirical coefficient, which equals to 0.01 and $C_{*}$ is the maximum static volume concentration for the sediment particles.

In Eq. (3), the first term represents the yield shear stress, which is the Mohr-Coulomb shear resistance, the second term is the viscous shear stress, the third term is the turbulent shear stress, and the fourth term is the dispersive shear stress. The above equation could be depth integrated and rewritten in the gradient form

$$
\begin{aligned}
S_{f} & =S_{y}+S_{v}+S_{t d} \\
& =\frac{\tau_{y}}{\gamma_{m} h}+\frac{K \eta u}{8 \gamma_{m} h^{2}}+\frac{n^{2} u^{2}}{h^{4 / 3}}
\end{aligned}
$$

where, $S_{y}$ is the yield gradient, $S_{v}$ is the viscous gradient, $S_{t d}$ is the turbulent-dispersive gradient, $\gamma_{m}$ is the specific weight of the sediment mixture, $K$ is the resistance parameter, and $n$ is the equivalent Manning value.

The yield stress $\tau_{y}$ and the viscosity $\eta$ vary principally with sediment concentration, and can be written in empirical relationships as,

$\tau_{y}=\alpha_{1} e^{\beta_{1} C}, \eta=\alpha_{2} e^{\beta_{2} C}$

$n=n_{t}+n_{d}=n_{t}+0.0538 n_{t} e^{6.0896 C}$

where $n_{t}$ is the turbulent Manning value and $n_{d}$ is the dispersive Manning value.

The yield and viscosity stresses in Eq. (6) appeared to be function of the volumetric sediment concentration, where the parameters $\alpha_{1}, \alpha_{2}, \beta_{1}$, and $\beta_{2}$ are empirical coefficients determined by laboratory experiment. O'Brien and Julien (1985) summarized results of some previous researches, and the values of these parameters were as listed in Table 1.

\section{Parametric study of yield stress and viscosity in rheo- logical model}

In order to understand the effects of parameters related to the yield stress and viscosity in the rheological model on the simulation results, the Jun-Kern watershed as shown in Fig. 1 was used for parametric study. The parameters proposed by Jang (1999) based on experiments using material obtained from Chui-Sue river watershed in the Chen-YouLan watershed were used as listed in Table 2 as the initial values. The simulation results indicated that depositing area 
Table 1. Parameters $\alpha_{1}, \alpha_{2}, \beta_{1}$ and $\beta_{2}$ in yield stress and viscosity (O'Brien and Julien, 1985).

\begin{tabular}{|c|c|c|c|c|}
\hline \multirow[b]{2}{*}{$\begin{array}{c}\text { Source } \\
\text { (1) }\end{array}$} & \multicolumn{2}{|c|}{$\tau_{y}=\alpha_{2} e^{\beta_{2} c_{v}}$} & \multicolumn{2}{|c|}{$\eta=\alpha_{1} e^{\beta_{1} c_{v}}$} \\
\hline & $\begin{array}{c}\alpha_{2} \\
\left(\text { dynes/cm }{ }^{2}\right) \\
(2)\end{array}$ & $\begin{array}{l}\beta_{2} \\
(3)\end{array}$ & $\begin{array}{c}\alpha_{1} \\
\text { (poises) } \\
(4)\end{array}$ & $\begin{array}{l}\beta_{1} \\
(5)\end{array}$ \\
\hline \multicolumn{5}{|c|}{ (a) Relationships Found in Field } \\
\hline Aspen Pit 1 & $1.81 \times 10^{-1}$ & 25.7 & $3.60 \times 10^{-2}$ & 22.1 \\
\hline Aspen Pit 4 & 2.72 & 10.4 & $5.38 \times 10^{-2}$ & 14.5 \\
\hline Aspen nature soil & $1.52 \times 10^{-1}$ & 18.7 & $1.36 \times 10^{-3}$ & 28.4 \\
\hline Aspen mine fill & $4.73 \times 10^{-2}$ & 21.1 & $1.28 \times 10^{-1}$ & 12.0 \\
\hline Aspen natural soil source & $3.83 \times 10^{-2}$ & 19.6 & $4.95 \times 10^{-4}$ & 27.1 \\
\hline Aspen natural fill source & $2.91 \times 10^{-1}$ & 14.3 & $2.01 \times 10^{-4}$ & 33.1 \\
\hline Glenwood 1 & $3.45 \times 10^{-2}$ & 20.1 & $2.83 \times 10^{-3}$ & 23.0 \\
\hline Glenwood 2 & $7.65 \times 10^{-2}$ & 16.9 & $6.48 \times 10^{-1}$ & 6.2 \\
\hline Glenwood 3 & $7.07 \times 10^{-4}$ & 29.8 & $6.32 \times 10^{-3}$ & 19.9 \\
\hline Glenwood 4 & $1.72 \times 10^{-3}$ & 29.5 & $6.02 \times 10^{-4}$ & 33.1 \\
\hline
\end{tabular}

(b) Relationships Found in Literature

\begin{tabular}{l|c|c|c|c}
\hline Iida (1938) & - & - & $3.73 \times 10^{-5}$ & 36.60 \\
\hline Dai et al. (1980) & 2.60 & 17.48 & $7.50 \times 10^{-3}$ & 14.39 \\
\hline Kang and Zhang (1980) & 1.75 & 7.82 & $4.05 \times 10^{-2}$ & 8.29 \\
\hline Qian et al. (1980) & $\begin{array}{c}1.36 \times 10^{-3} \\
5.0 \times 10^{-2}\end{array}$ & $21.2 \sim 15.48$ & - & - \\
\hline Chien and Ma (1958) & $5.88 \times 10^{-2}$ & $19.1 \sim 32.70$ & - & - \\
\hline Fei (1981) & $\begin{array}{c}1.66 \times 10^{-1} \\
4.7 \times 10^{-3}\end{array}$ & $25.6 \sim 22.20$ & - & - \\
\hline
\end{tabular}

increases and volume of deposition decreases with increasing parameters $\alpha_{1}$, and $\beta_{1}$, especially with parameter $\beta_{1}$. While increases of parameters $\alpha_{2}$, and $\beta_{2}$ lead to increases of deposit area and deposit volume, especially deposit volume. The depth of wave front increases with increasing parameter $\beta_{2}$, and the wave front is also pushed forward. However, the increases of parameter $\beta_{2}$ have no effects on the expansion of the alluvial fan transversely.

Analysis on the other nine subwatersheds of Chen-YouLan watershed as shown in Fig. 1 was then performed using the same initial set of parameters. However, in the research by Jang (1999), the specimen was reconstituted using material with uniform and smaller grain size particles compared to field deposition. Therefore, adjustments of the parameters were made empirically such that the resulting deposition condition would be similar to the field observation in each case. The rheological parameters thus obtained for each site are shown in Table 3. Although the rheological parameters appeared to vary, most of the values are still within reasonable range as compared to that of Table 1 . Accordingly it is
Table 2. Rheology parameters of materials from Chui-Sue river watershed (Jang, 1999).

\begin{tabular}{ccccc}
\hline & $\alpha_{1}$ (poises) & $\beta_{1}$ & $\alpha_{2}\left(\right.$ dyne $\left./ \mathrm{cm}^{2}\right)$ & $\beta_{2}$ \\
\hline Value & 0.00462 & 11.24 & 0.6488 & 13.72 \\
\hline
\end{tabular}

suggested that adjustment of rheological parameters should take into account the properties of debris, debris composition, and the relief of the deposit area.

\section{Micro-geomorphic analysis of the Chui-Sue River wa- tershed}

The Chui-Sue river watershed is located in the southwestern part of Chen-You-Lan watershed up-stream of Her-Ser River, and along the new trans-island highway of Taiwan as shown in Fig. 1. Originating at $2287 \mathrm{~m}$ above sea level, the Chui- 
Table 3. Rheological parameters from back analysis of subwatersheds.

\begin{tabular}{lllllll}
\hline Debris Flow Site & $\begin{array}{l}\text { Basin Area } \\
\left(\mathrm{km}^{2}\right)\end{array}$ & Debris composition & $\begin{array}{l}\alpha_{1} \\
(\text { poises })\end{array}$ & $\beta_{1}$ & $\begin{array}{l}\alpha_{2} \\
\left(\mathrm{dyne} / \mathrm{cm}^{2}\right)\end{array}$ & $\beta_{2}$ \\
\hline Nan-Ping-Kern & 1.42 & Clay, Sand and Gravel & 0.001386 & 3.372 & 0.24330 & 4.116 \\
Jun-Kern & 0.81 & Clay, Sand and Gravel & 0.004158 & 10.116 & 0.72990 & 12.348 \\
Err-Bu & 1.63 & Clay, Sand and Gravel & 0.004158 & 10.116 & 0.72990 & 12.348 \\
Shan-Bu & 3.68 & Clay, Sand and Gravel & 0.002310 & 5.620 & 0.40550 & 6.860 \\
Fong-Chu & 1.67 & Quartzite sandstone, slate & 0.004851 & 11.802 & 0.85155 & 14.406 \\
Tung-Fu Community & 0.69 & Sandstone, shale & 0.004620 & 11.240 & 0.81100 & 13.720 \\
Her-Ser 1 & 1.67 & Sandstone, shale & 0.006000 & 14.612 & 1.05430 & 17.836 \\
Her-Ser 3 & 3.22 & Sandstone, shale & 0.004620 & 11.240 & 0.81100 & 13.720 \\
Chui-Sue River & 8.55 & Sandstone, shale & 0.924000 & 14.612 & 1.26520 & 16.464 \\
\hline
\end{tabular}

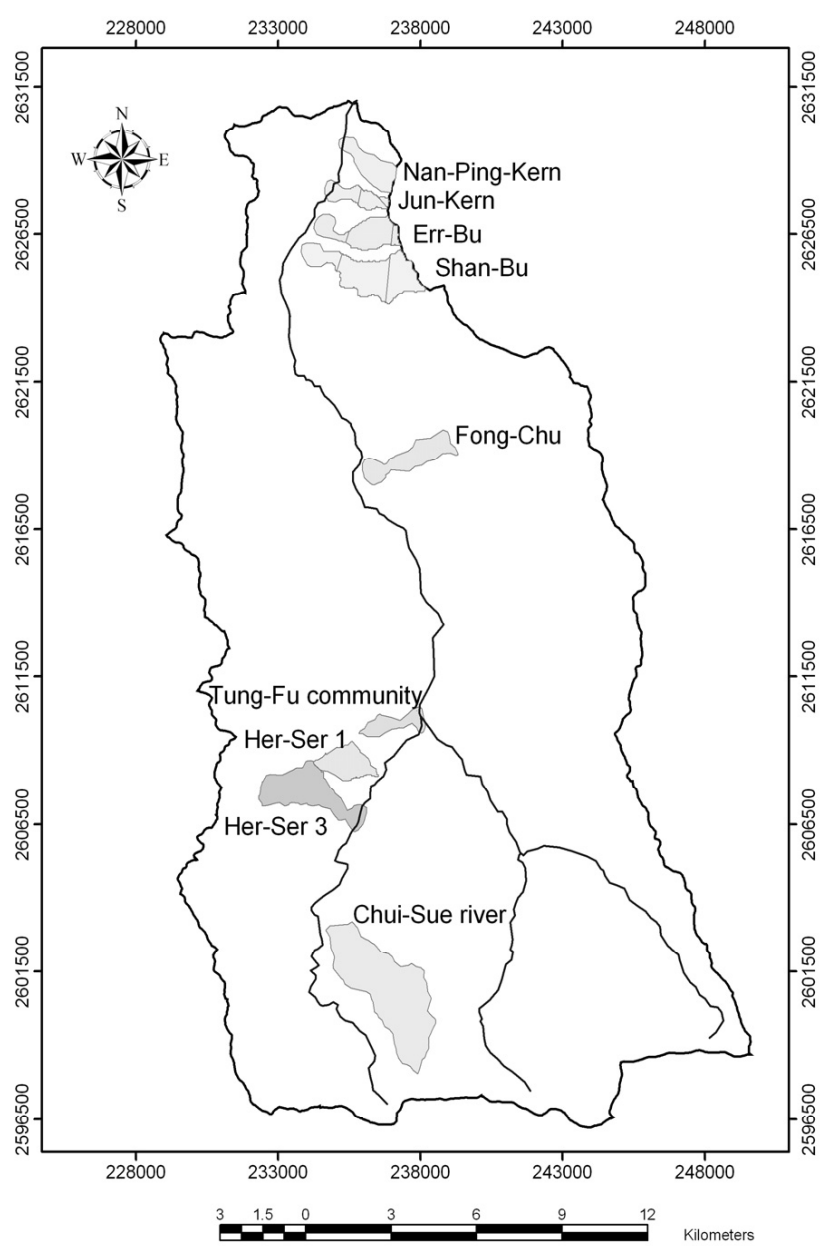

Fig. 1. Study areas in Chen-You-Lan river watershed.

Sue River drains approximately $8.55 \mathrm{~km}^{2}$ of steep terrain as shown in Fig. 2. The average slope angle of Chui-Sue River watershed is $12.2^{\circ}$. The rock formation of the watershed was mainly inter-beded sandstone and shale of the Tertiary HerSer and Nan-Chuang formations with little or no metamorphic action. The geological conditions of the area were fairly fractured with old landslide in the up-stream area. On 31 July

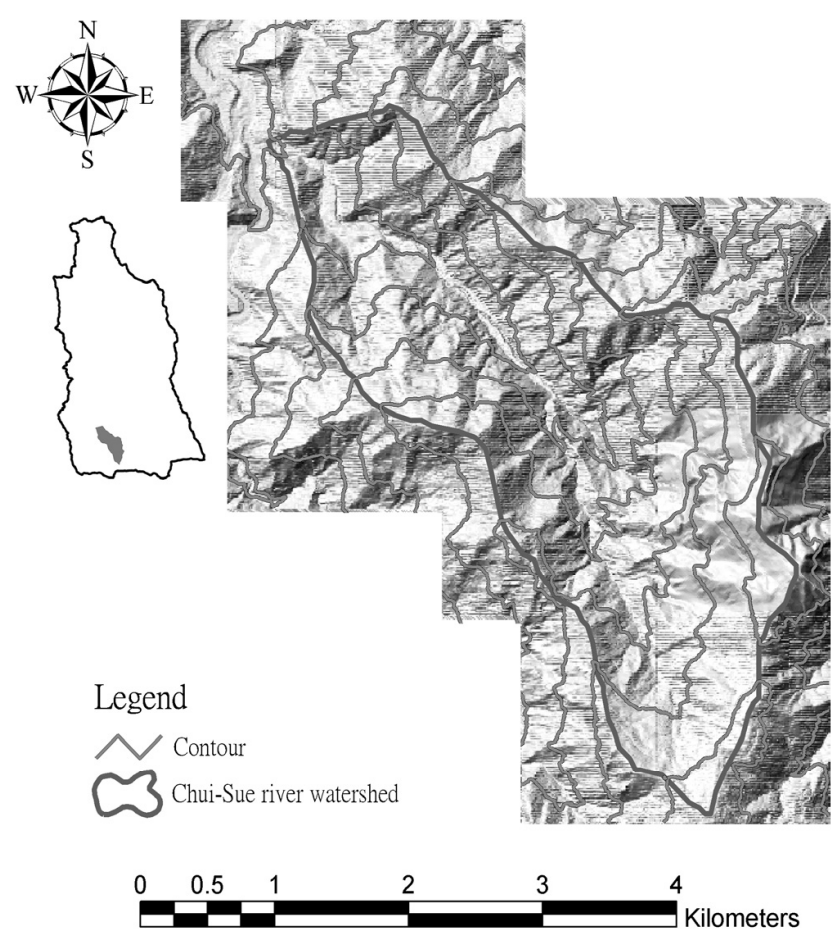

Fig. 2. The Chui-Sue river watershed.

1996, severe debris flow occurred in this area when typhoon Herb struck the central Taiwan. Several incidents of debris flow occurred since then, in May 1998, the Her-Ser bridge crossing the Chui-Sue River was raised and pushed sideway due to damming up of the debris under the bridge.

The digital terrain models of the Chui-Sue River watershed with a resolution of $10 \mathrm{~m}$ by $10 \mathrm{~m}$ were generated using the aerial photos taken before (1993) and after typhoon Herb (1996), respectively. The micro-geomorphic analysis was performed on the Chui-Sue River watershed and the downstream area of the river, which is the Shen-Mu area, by comparing the terrains before and after the debris flow. The purpose of the micro-geomorphic analysis is to study the erosion and deposition conditions in the watershed caused by 
Table 4. Areas and corresponding volumes of material erosion and deposition.

\begin{tabular}{lccccc}
\hline & $\begin{array}{c}\text { Triggering } \\
\text { area }\end{array}$ & $\begin{array}{c}\text { Flow } \\
\text { area }\end{array}$ & $\begin{array}{c}\text { Deopsition } \\
\text { area }\end{array}$ & $\begin{array}{c}\text { Landslide } \\
\text { area }\end{array}$ & Total \\
\hline Volume of deposition $\left(\mathrm{m}^{3}\right)$ & 833287 & 922494 & 3361815 & 5904 & 5123500 \\
Projection area of deposition $\left(\mathrm{m}^{2}\right)$ & 453083 & 362462 & 907953 & 3452 & 1726950 \\
Surface area of deposition $\left(\mathrm{m}^{2}\right)$ & 475464 & 394211 & 942816 & 4340 & 1816831 \\
Volume of erosion $\left(\mathrm{m}^{3}\right)$ & 5066358 & 2413641 & 599183 & 77215 & 8156397 \\
Projected area of erosion $\left(\mathrm{m}^{2}\right)$ & 1064518 & 626037 & 180399 & 18048 & 1889002 \\
Surface area of erosion $\left(\mathrm{m}^{2}\right)$ & 1154291 & 669833 & 201544 & 21337 & 2047005 \\
\hline
\end{tabular}

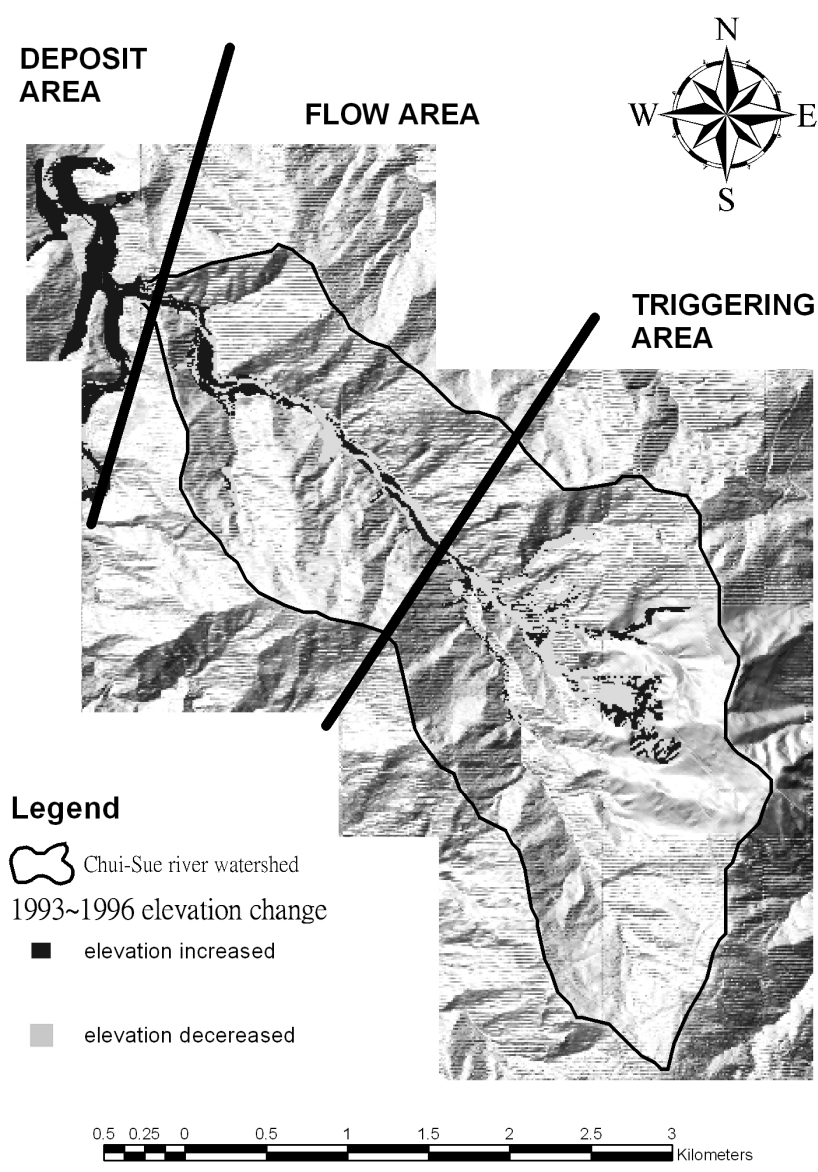

Fig. 3. Results of micro-geomorphic analysis of the Chui-Sue River watershed.

the debris flow. From the conditions of erosion and deposition, the triggering area, flow area, and the deposit area in the watershed along the debris flow river can be identified. Through the study, the affected areas, the amount of material erosion, and the amount of material deposition at the downstream area could be determined, and which could provide information for the subsequent simulation and verification.

By running a comparison of the elevations for each grid point with the same coordinates, the changes of the geomorphic condition of the area were established. It was found

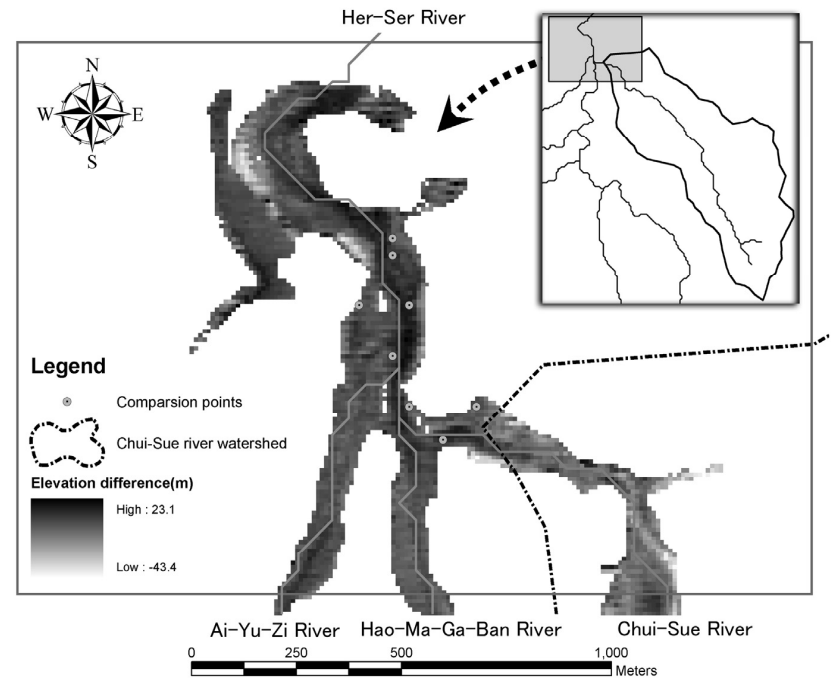

Fig. 4. Distributions of average thickness of deposition and erosion along Chui-Sue River from micro-geomorphic study.

that riverbed became wider and deeper, and the cross section changed from a V-shape into a U-shape after the Typhoon struck. The triggering area was identified as the area where the major action was erosion, the flow area was identified as the area where both erosion and deposition actions occurred and were about balanced, and the deposit area was identified as the area where the major action was deposition according to the characteristics of debris flow action. The resulting triggering area, flow area, and deposition area of Chui-Sue River watershed are as shown in Fig. 3. The affected areas and volumes of the material eroded and deposited in each portion along the river are computed using the variations of the DTM before and after the debris flow, and results are listed in Table 4 . It is noted that the total volume of material erosion is higher than the total volume of material deposition. This may due to that the eroded material could be carried further downstream by the flow or subsequent water flow without depositing in the deposition area. The results presented in Table 4 may be affected by other ground variations of the area depending on the time the aerial photos were taken; however, they still provide good references for the terrain variations caused by debris flow. 
Table 5. Comparisons of deposition thickness and area.

\begin{tabular}{|c|c|c|c|c|}
\hline \multirow[t]{2}{*}{ Grid ID } & \multicolumn{2}{|c|}{ Thickness of deposit (m) } & \multirow{2}{*}{$\begin{array}{l}\text { Percentage } \\
\text { error }(\%)\end{array}$} & \multirow[t]{2}{*}{ Remarks } \\
\hline & Numerical model & $\begin{array}{l}\text { Micro-geomorphic } \\
\text { study }\end{array}$ & & \\
\hline 1696 & 0.39 & 5.18 & -92.47 & $\begin{array}{l}\text { Shen-Mu Elementary } \\
\text { School }\end{array}$ \\
\hline 1626 & 8.95 & 9.02 & -0.78 & Her-Ser Bridge \\
\hline 1560 & 3.29 & 3.62 & -9.12 & \\
\hline 1529 & 4.91 & 6.98 & -29.66 & \\
\hline 1566 & 8.36 & 8.73 & -4.24 & \\
\hline 1464 & 4.22 & 4.63 & -8.86 & \\
\hline 1535 & 12.34 & 8.72 & 41.51 & \\
\hline 1536 & 5.43 & 2.45 & 121.63 & \\
\hline Deposition Area $\left(\mathrm{m}^{2}\right)$ & 162331 & 198100 & -18.06 & \\
\hline
\end{tabular}

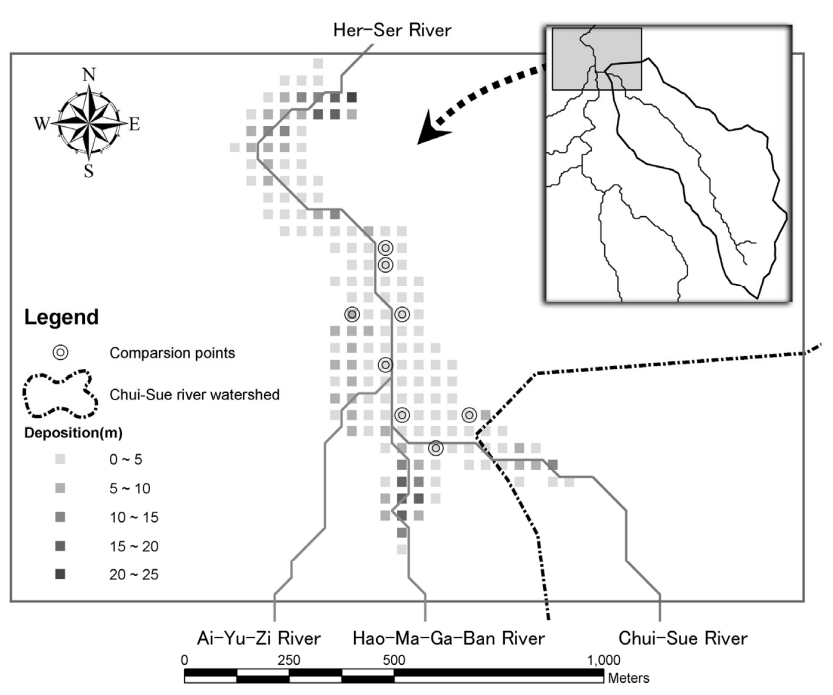

Fig. 5. Results of the numerical simulation.

\section{Debris flow simulation of the Chui-Sue River water- shed}

In order to compare the field condition with the numerical results, the average thickness of deposition and erosion of each grid area was computed from the micro-geomorphic analysis and was plotted as shown in Fig. 4. Numerical simulation of the Chui-Sue river watershed was performed using the parameters listed in Table 3. For the simulation, the hydrograph was produced for the basin based on the precipitation record of Typhoon Herb, and the debris flow simulation was conducted by assigning sediment concentration and the resulting debris flow hydrograph starting from the deposition area as identified in Fig. 3. Results of the numerical simulation are as shown in Fig. 5. Comparing Fig. 5 to the deposition area of micro-geomorphology study, the affected area appeared to be fairly consistent, but the thickness of deposition varied. In

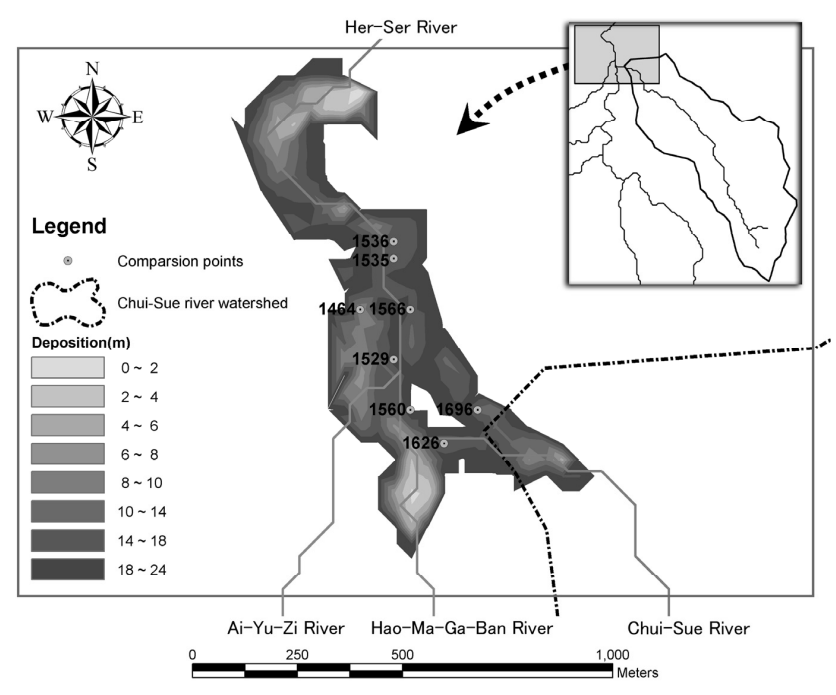

Fig. 6. Locations of grid point and thickness of deposition for comparison.

order to have more detailed comparisons, eight grid points along the Chui-Sue River and Her-Ser River in the downstream area were selected where the thickness of deposition and its impact were significant. Locations and resulting depths of deposition plotted as contour are as shown in Fig. 6 . Noted that in the deposition area further downstream of the Chui-Sue River, the Hao-Ma-Ga-Ban River merged into HerSer River just upstream from grid point 1560, and Ai-Yu-Zi River also merged into Her-Ser River next to the grid point 1529. Both rivers have records of producing debris flow, and the influx of the two rivers would contribute to the variations of deposition in the area. Comparisons of the thickness of deposition from numerical simulation and micro-geomorphic analysis of the eight grid points are as listed in Table 5. Observing the differences between thicknesses from the model simulation and micro-geomorphic study, results of locations 
1626 and 1566 appeared to be very consistent, and results of locations 1560 and 1464 are also reasonably consistent. Location 1696 is at the Shen-Mu elementary school, which is on the riverbank and protected by embankment. In the numerical model, the local topography changes caused by man-made structures such as embankment were not considered, and thus introducing a large difference in thickness of deposition. In addition, the differences for locations 1529 , 1535, and 1536 are significant, and as moving further downstream the difference appeared to increase. From the area map as displayed in Fig. 6, the Chui-Sue River merged into the Her-Ser River at the location neighboring to 1560, and was joined by the Hao-Ma-Ga-Ban River and Ai-Yu-Zi River further downstream. As the thickness of deposit derived from the model simulation was based on the debris flow from Chui-Sue River only, therefore the effects of effluence from the two streams were not accounted for. However, in the micro-geomorphic analysis, the terrain variations caused by all other streams were included. It was likely that the effluence of the other streams could affect the debris deposition thickness because the other two streams could either produce debris flows or wash the debris deposition away. As moving further downstream of the Her-Ser River, the debris could be washed away by the river flow, for locations 1535 and 1536 displaying larger thickness from model simulation than micro-geomorphology study. For the study area, the total area of deposition from numerical simulation was about $18 \%$ larger than that of the micro-geomorphic analysis, and may due to the reason as discussed above. The trend of thickness and area of deposition obtained from the model simulation appeared to be fairly consistent with the micro-geomorphic data especially for the upstream area not affected by other inflow rivers.

\section{Conclusions}

Based on previous discussions, the modeling procedures for debris flow simulation were established using FLO-2D, and it was found that the parameters for the yield and viscous stresses have significant effects on the simulation results. Laboratory testing conditions were often very different from the field condition, which results in very different parameters, and the adjustment of rheological parameters should take into account the properties of debris, debris composition, and the relief of the deposit area. The results of rehological parameters adjustment in this study can provide references for other cases with the similar geological conditions.
A case study based on the comparison of Microgeomorphology study and numerical simulation of Chui-Sue river watershed suggested that with proper parameters, the numerical model could provide reasonably good results for identifying the affected area and thickness of deposition in the affected area, which would be very helpful for debris flow hazard mitigation.

Edited by: M. Arattano

Reviewed by: two referees

\section{References}

Arrattano, M. and Franzi, L.: On the evaluation of debris flows dynamics by means of mathematical models, Nat. Hazards Earth Sys. Sci., 3, 539-544, 2003,

SRef-ID: 1684-9981/nhess/2003-3-539.

Bingham, E. C. and Green, H.: Paint, a plastic material and not a viscous liquid; the measurement of its mobility and yield value, Proceeding of American Society of Testing Material, Part II, 19, 640-664, 1919.

Chen, H. and Lee, C. F.: Runout analysis of slurry flows with Bingham model, Journal of Geotechnical and Geoenvironmental Engineering, 128, 12, 1032-1042, 2002.

Herschel, W. H. and Bulkley, R.: Measurement of consistency as applied to rubber-benzene solutions, Proceeding of American Society of Testing Material, Part II, 26, 621-633, 1926.

Hübl, J. and Steinwendtner, H.: Two-dimensional simulation of two viscous debris flows in Austria, Physics and Chemistry of the Earth, 26, 9, 639-644, 2001.

Jang, C. D.: An Experimental Study on Debris-Flow Rheology and Behaviors, project report of National Science Council, Taiwan, 1999.

Johnson, A. M.: Physical processes in geology, Freeman, Cooper \& Company, 431-459, 1970.

Lin, M.-L., Wang, K.-L., and Huang, G.-J.: Simulation and Analysis of Debris Flow of Chui-Sue River Watershed, Proceedings of the Third International Conference on Watershed Management, 69-79, 2001.

O'Brien, J. S. and Julien, P. Y.: Physical process of hyperconcentrated sediment flows, Proceedings of the ASCE Specialty Conference on the Delineation of Landslides, Floods, and Debris Flow, 260-279, 1985.

Uddin, M. S., Inaba, H., Yoshida, Y., Itakura, Y., and Kasahara, M.: Large motion estimation by gradient technique - Application to debris flow velocity field, Phys. Chem. Earth, Part C, 26, 9, 633638, 2001.

Franzi, L. and Bianco, G.: A statistical method to predict debris flow deposited volumes on a debris fan, Phys. Chem. Earth, Part C, 26, 9, 683-688, 2001. 